\title{
A formação na Licenciatura em Educação do Campo para atuar com a disciplina de Física na Educação Básica
}

\section{Graduation training in Rural Education to act wit the discipline of Physics in Basic Education}

\author{
Marcos Marques Formigosa (mformigosa@ufpa.br) \\ Faculdade de Etnodiversidade, Universidade Federal do Pará \\ Carla Giovana Souza Rocha (crocha@ufpa.br) \\ Faculdade de Etnodiversidade, Universidade Federal do Pará \\ Márcio Rogério da Silva (marciomrs@ufpa.br) \\ Faculdade de Etnodiversidade, Universidade Federal do Pará
}

\begin{abstract}
Resumo: Os cursos de Licenciatura em Educação do Campo têm, entre os seus diferenciais, a formação por área de conhecimento, dentre elas, a de Ciências da Natureza, que, em alguns Projetos Pedagógicos de Cursos (PPC), habilita os egressos para atuarem no Ensino Médio com as disciplinas escolares de Biologia, Química e Física. Nesse sentido, o objetivo desta pesquisa é investigar como vem ocorrendo a formação do professor que atuará na disciplina de Física, da Educação Básica, a partir de um curso de Licenciatura em Educação do Campo. A técnica de produção de informação foi de pesquisa documental em bancos de dados dos Censos da Educação Superior e da Educação Básica, de 2018 e 2019, respectivamente, além do PPC de um curso de Educação do Campo em funcionamento no interior do Estado do Pará. Esses dados foram analisados numa perspectiva qualitativa e mostram que há um percentual elevado de professores que atuam nessa disciplina sem formação adequada, dado o baixo número de docentes de Física que se formam no País. Esse percentual fica mais acentuado quando olhamos para os professores atuantes nas escolas do campo. Ademais, mostra que a carga horária das atividades curriculares no curso de Educação do Campo destinada à disciplina de Física é muito baixa, correspondente a apenas 7,2\% do total, além dos conteúdos presentes nas ementas dessas atividades serem predominantes da Física clássica, sugerindo que não há abordagem que os relacione com os modos de vida dos sujeitos do campo.
\end{abstract}

Palavras-chave: Educação do Campo; Formação de Professor; Professor de Física.

Abstract: The Graduation's courses in Rural Education have, among its differentials, the training by knowledge area, among them, the Nature Sciences which, in some Pedagogical Projects of Courses (PPC), enables the egresses to work in High School with the scholars disciplines of Biology, Chemistry and Physics. In this sense, the objective of this research is to investigate how has been occurring the training of the teacher who will work in the discipline of Physics, at Basic Education, from a Degree course in Rural Education. The information production technique was documentary research in databases 
of Census of Higher Education and Basic Education, from 2018 and 2019, respectively, besides a PPC of a Rural Education course which is functioning in the interior of the State of Pará. These data were analyzed in a qualitative perspective and show that there is a high percentage of teachers who work in this discipline without proper training due the low quantity of teachers of Physics who graduate in the country. This percentage becomes more accentuated when we look at active teachers in the rural schools. In addition, it shows that the workload of the curricular activities in the Rural Education course destined to the Physics discipline is too low corresponding only to $7,2 \%$ of the total, besides the contents which are in these activities menus be predominant of the classic Physics suggesting that there is no addressing which connect them with the ways of life of the country man.

Keywords: Rural Education; Teacher training; Physics Teacher

\section{INTRODUÇÃO}

O Movimento Por uma Educação do Campo, ao longo dos seus 20 anos de existência, tem como uma de suas lutas principais a construção de políticas públicas que garantam o direito à população do campo a uma escola e a uma educação 'do' campo e 'no' campo que além de formar os sujeitos para a cidadania, lhes dê condições para dar continuidade nos estudos. Para tanto, demanda por professores com formação específica e diferenciada, como recomenda a Lei de Diretrizes e Bases da Educação NacionalLDBEN (BRASIL, 1996).

Tâl formação se sustenta em um dós pressupostos da Educação do Campo: a formação identitária dos sujeitos a partir dos múltiplos espaços (sociais, religiosos, políticos, culturais, agrícolas, etc.), considerados indissociáveis e complementares. Logo, não se visualiza a escola do campo sem o vínculo das práticas por ela desenvolvidas com os modos de vida da comunidade, pois, como pontua Arroyo (2009), ela se constitui para além do espaço fechado da sala de aula, que pode ser mediada pela Pedagogia da Alternância, que propõe a articular os saberes dos sujeitos, com os conteúdos curriculares, nos tempos-espaços distintos visando romper com o modelo de educação bancária (FREIRE, 1996), que prevalece em muitas escolas do campo.

Esse movimento demanda por profissionais que tenham a sensibilidade de abrir espaços para experienciar outras formas de ensinar e aprender, em especial em disciplinas que, historicamente, se desenvolveram num modelo cartesiano, como aquelas da área das ciências da natureza. Além dessa herança cartesiana, as escolas do campo possuem 
carência de professores com formação específica, ocasionando a atuação de docentes sem a formação específica, como preconiza a LDBEN (TENÓRIO et al., 2019) e em muitos casos, por não se ter professor habilitado ou disponível para atuar, os alunos sequer cursam as disciplinas dessa área (ANDRADE, 2020).

Não é nossa intenção fazer comparações entre os cursos de Licenciatura em Física e Licenciatura em Educação do Campo, pois, mesmo que tais cursos tenham a mesma finalidade (a formação de professores), cada um deles tem as suas especificidades, assim como as demais licenciaturas. No entanto, enquanto a Licenciatura em Física prima pela presença de determinados conteúdos, tidos como clássicos, para serem abordados em sala de aula, como parte fundamental da aprendizagem, a Educação do Campo, por sua vez, busca construir uma formação pautada em um modelo de sociedade humana e solidária, a partir de uma perspectiva educacional capaz de inserir o sujeito do campo como protagonista do seu processo formativo e não apenas ser um mero receptor de informações, que podem ser transmissíveis de qualquer forma, sem que se considere as especificidades e diversidade dos sujeitos.

É a partir de demandas como essas que os cursos de Licenciatura em Educação do Campo foram se constituindo, desencadeando limites e possibilidades para a formação do professor para atuar nas escolas do campo, frente às lacunas em algumas disciplinas na educação básica, como a Física. A discussão se assenta na questão de que os cursos de Educaçã́ do Campo se propõem a formar por área de conhecimento, numa perspectiva interdisciplinar, mostrando-se com um grande desafio, tanto no âmbito da sua construção curricular, quanto do percurso formativo. Britto e Silva (2015) pontuam, por exemplo, que a formação por área vem sendo palco de estudos inerentes ao currículo, às práticas docentes, ao campo de atuação dos egressos e a ruptura ao modelo cartesiano disciplinar existente no interior das universidades brasileiras.

Além disso, um outro fator que chama atenção são os professores que atuam nesses cursos de Licenciatura em Educação do Campo, pois parte considerável deles veio de formações disciplinares distintas e pouco ou nada conheciam tanto da experiência formativa da educação do campo, quanto da formação por área do conhecimento, em especial aqueles da área de ciências da natureza (BRICK; BORGES, 2017). Outras lacunas foram percebidas quando da nossa imersão no percurso formativo, em especial 
no que concerne ao tempo e aos conteúdos a serem abordados, inerentes às Ciências da Natureza, mais precisamente em Física.

O objetivo desta pesquisa é analisar como vem ocorrendo a formação do professor que atuará na disciplina de Física da educação básica a partir de um curso de Licenciatura em Educação do Campo. Além desta introdução, o texto está estruturado por uma explanação sobre a formação por área do conhecimento a partir da experiência do curso de Educação do Campo; logo em seguida será apresentado o percurso metodológico; posteriormente discutimos os dados oriundos da pesquisa documental, tanto dos censos quanto da análise do PPC; e por fim, as considerações finais.

\section{A FORMAÇÃo POR ÁREA dO CONHECIMENTO NO CURSO DE LICENCIATURA EM EDUCAÇÃO DO CAMPO}

Os cursos de Licenciatura Educação do Campo foram planejados para serem desenvolvidos por área do conhecimento, a saber: Linguagens e Códigos; Ciências da Natureza; Ciências Humanas e Sociais; Matemática e Ciências Agrárias. Os quais habilitam os egressos a atuarem nos anos finais do ensino fundamental e no ensino médio. Esses cursos iniciam em 2005 como experiência piloto na UFMG, UnB, UFBA e UFS. Posteriormente, em 2007, ocorreu a criação do Programa de Apoio à Formação Superior em Licenciatura em Educação do Campo (PROCAMPO) com a abertura de editais nos anos de 2008 e 2009, para apoiar a oferta dessas Licenciaturas nas instituições de ensino superior, para tanto, destinavam recursos específicos para a sua operacionalização.

No entanto, eram programas pontuais, com recursos destinados para turmas únicas e, apenas em 2012, por meio do Edital n ${ }^{\circ}$ 02/2012 ${ }^{1}$ - SESU/SETEC/SECADI/MEC, as instituições federais de ensino submeteram propostas de criação do curso de Licenciatura em Educação do Campo que abarcassem a formação por área de conhecimento, e em contrapartida, o MEC disponibilizaria 15 vagas de docentes e 3 vagas de técnicos administrativos em educação para cada projeto aprovado (MOLINA, HAGE, 2016; MEDEIROS; MORENO; BATISTA, 2020). Essa iniciativa surgiu como forma de implementar a política pública de educação do campo que prevê, dentre as suas ações, a

\footnotetext{
1 Disponível em: $\quad$ http://portal.mec.gov.br/index.php?option=com docman\&view= download\&alias=13300-edital-02-2012-sesu-setec-secadi-31-agosto-2012-pdf\&category_slug=junho2013-pdf\&Itemid=30192. Acesso em: 20 out. 2020.
} 
oferta de formação inicial e continuada de professores para as escolas do campo, em atendimento ao Decreto $\mathrm{n}^{\circ}$ 7.352/2010 (BRASIL, 2010), e cumprir o que determina o Art. $6^{\circ}$ das Diretrizes Operacionais da Educação Básica nas Escolas do Campo ${ }^{2}$ (CALDART, 2015). Ao todo foram aprovados 42 projetos, sendo três deles da UFPA.

Mas, por que formar por área do conhecimento e não por disciplinas específicas? Esse questionamento se faz necessário para compreendermos que a construção desse curso, no interior das universidades, se deu de forma coletiva, envolvendo tanto os movimentos sociais - que foram os primeiros a tensionarem o governo sobre a necessidade de oferta dos anos finais do ensino fundamental e do ensino médio nas escolas do campo, nível de escolaridade em que as populações são majoritariamente desassistidas - quanto as instituições de ensino e pesquisa, como as universidades públicas. Além de ter seguido um caminho diferente frente às outras licenciaturas, dada as suas finalidades que perpassa pela carência de professores em determinadas disciplinas, bem como uma formação alicerçada nos modos de vida dos sujeitos do campo, que se sustenta na Pedagogia da Alternância, constituída por tempos formativos distintos, complementares e interdependentes.

Um dos motivos que ocasionava essa lacuna era a ausência de professores qualificados para atuarem nas escolas do campo, obrigando os alunos a se deslocarem para as cidades em busca de escola - seja de forma definitiva, com toda a família, ou de forma pendualar $\mathrm{n}$ pormeio do transporte escolar, nem sempre adequado, ou em trajetos muito longos, dada as distâncias existentes entre as comunidades de pertença dos alunos e a escola, conforme aponta Andrade (2020):

[...] em muitos casos, por não ter oferta dessa modalidade de ensino, os pais se veem obrigados a mandarem seus filhos para estudarem nas cidades, em casas alugadas, nas casas de vizinhos, desconhecidos ou parentes. Há ainda casos em que a distância existente entre as comunidades rurais (com EM) ou entre as comunidades e a cidade são muito grandes, ou em que a trafegabilidade das estradas no período de chuvas fica mais difícil, ou ainda pela ausência de transporte escolar, a alternativa encontrada por algumas famílias é buscar a escola na cidade, em muitos casos, vendendo a propriedade e se mudando para a área urbana (p. 14).

\footnotetext{
${ }^{2}$ Resolução no 01/2002 - CNE/CEB/MEC (BRASIL, 2002).
} 
O autor salienta ainda que na região da Transamazônica ${ }^{3}$ isso se torna mais acentuado no ensino médio, que ocorre em agrovilas, por meio do Sistema de Organização Modular de Ensino (SOME) ${ }^{4}$ (ANDRADE, 2020). Assim, a formação de professores para atuar nesses espaços passou a ser concebida enquanto política pública, a partir das experiências pilotos desenvolvidas nas universidades, que possuíam fortes relações com os movimentos sociais do campo e com suas práticas em educação (BRITTO; SILVA, 2015; MOLINA; HAGE, 2015; HAGE; SILVA; BRITTO, 2016).

Tais experiências propuseram a formação de sujeitos concebendo os distintos espaços de formação (seja na universidade ou na comunidade de pertença), a partir do contexto camponês, que dialogassem com o campo e os modos de vida e de trabalho. Além disso, pautava-se numa formação que fosse capaz de pensar o campo e a escola do campo numa perspectiva diferente do modelo urbano implementado nas comunidades rurais, e que estavam em desacordo com as normas e legislações vigentes.

É nessa mesma direção que Britto (2016) salienta que a formação aos moldes das licenciaturas disciplinares não permitiria o tratamento às especificidades do campo, porque as referências dessas licenciaturas recaem em legislação e diretrizes curriculares próprias, não permitindo a inserção de outros elementos no processo formativo, como a alternância entre os tempos e os espaços. Era necessário fazer rupturas com esses modelos que não conseguem dar conta da formação em áreas fundamentais para os alunos da educaçã่o básica, mais precisamente à̀quelè que residente no campo.

Para tanto, Britto e Silva (2015) explanam que a formação por área de conhecimento deveria englobar uma relação dialógica com as concepções Freireanas, em que os saberes e viveres do contexto camponês se materializassem no processo formativo e refletissem na escola, a partir da alternância entre tempos e espaços formativos, como forma de valorização dos modos de vida dos sujeitos do campo. Além disso, Caldart (2015) salienta que é preciso compreender a realidade e os modos como os sujeitos do

\footnotetext{
${ }^{3}$ A rodovia Transamazônica (BR 230) inicia no estado da Paraíba, passando pelos estados do Piauí, Maranhão, Pará e Amazonas. A região Transamazônica a qual nos reportamos compreende o trecho entre os municípios de Pacajá (PA) e Placas (PA), perímetro de abrangência do Campus da UFPA/Altamira.

${ }^{4}$ O SOME foi criado em 1980 no Estado do Pará, com objetivo de ofertar educação básica às comunidades camponesas de difícil acesso. As disciplinas são ofertadas por meio de módulos, com cada um correspondente a 45 dias letivos, e engloba 3 disciplinas curriculares de áreas afins
} 
campo produzem conhecimento, como forma de se estabelecer relações entre a educação e o desenvolvimento das comunidades.

As assertivas das autoras Caldart (2015), Britto e Silva (2015) e Britto (2016) seguem na direção daquilo que recomenda o Art. 28 da LDB e o Decreto $n^{\circ} 7.352 / 2010$. Neste decreto, dentre os princípios apontados para a educação do campo, o Parágrafo $1^{\circ}$ assegura que a oferta da educação aos sujeitos do campo deve ocorre com: "respeito à diversidade do campo em seus aspectos sociais, culturais, ambientais, políticos, econômicos, de gênero, geracional e de raça e etnia" (BRASIL, 2010).

Outro motivo apontado pela autora recai sobre a demanda de alunos, logística e investimento em manter um único professor de uma determinada disciplina específica em uma comunidade rural, pois

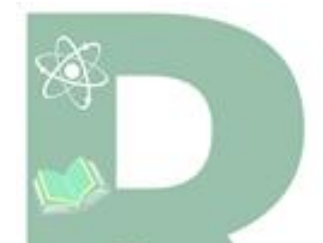

[...] um dos problemas alegados para garantir escolas de educação básica completa nas comunidades camponesas é a inviabilidade de manter um professor por disciplina em escolas que nem sempre conseguem ter um número grande de estudantes e cuja localização torna mais difícil a lógica de cada professor trabalhar em diversas escolas para completar sua carga horária (CALDART, 2015, p. 7, grifos nosso).

Assim, percebemos que a formação por área de conhecimento tornou-se uma ação estratégica, que conseguiu abarcar, dentro de uma única proposta, elementos que visam suprir: a falta de professores para atuar nos anos finais do ensino fundamental e no ensino médio; uma formação que dialogue com os modos de vida dos sujeitos do campo; e a ruptura aos modelos de escolas que são introduzidos nas comunidades rurais, importadas do modelo urbano (BRICK; BORGES, 2017).

E tais temáticas não são pautadas em cursos em que a formação se dá de forma convencional, por meio de formação disciplinar, como a licenciatura em Física, por exemplo, não abrindo margens para que se insira, dentro dos seus currículos, elementos dessa natureza por serem consideradas no âmbito acadêmico como áreas "duras". Moreira (2018) pontua que isso é um dos elementos que tem ocasionado um elevado número de evasão nesse curso, pois o mesmo parece não estar aberto para a inserção de perspectivas contemporâneas na formação docente, capaz de mudar seu currículo tanto no aspecto conceitual das disciplinas, quanto epistemológico e didático.

Nesse sentido, Britto e Silva (2015) entendem que, a formação por área do conhecimento acabou se estabelecendo como via para a garantia de direito da oferta do 
ensino fundamental e médio nas escolas do campo. Além disso, a proposta formativa transcende a interdisciplinaridade das três disciplinas que constituem a área (Biologia, Física e Química, por exemplo) e consegue trazer para o processo formativo outros elementos que perpassam por outras disciplinas, como História, Geografia e Matemática, por exemplo.

É nesse cenário que a Educação do Campo adentra, com a perspectiva de formar professores que, além de suprir uma demanda reprimida em algumas disciplinas, como a Física, também proporciona uma formação aos sujeitos do campo de forma específica e diferenciada. Essa iniciativa permite aos alunos da educação básica ter um professor que tenha formação na sua disciplina de atuação e com sensibilidade para as especificidades inerentes à atuação docente nas escolas do campo, que transcorre nos distintos espaços.

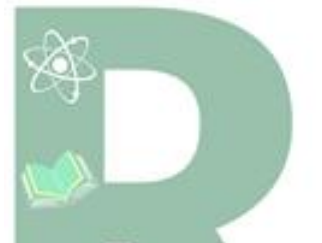

É nesse contexto que está a organização curricular por área do conhecimento, que tem neste curso como desafio principal a habilitação para a docência por área, mas também a organização do estudo para além das aulas, e as aulas para além de um ensino apenas transmissivo, mas que não descuidem da apropriação do conhecimento historicamente produzido pela humanidade e que ajudem na compreensão da realidade que precisamos transformar (CALDART, 2015, p. 6, grifos nossos).

E um dos caminhos encontrados para essa formação, nesses distintos espaços e momentos que se desenvolvem por meio da Pedagogia da Alternância, tem os Tempos Universidade (TU) e Tempos Comunidades (TC) como partes indissociáveis e complementares desse processo. Essaciniciativa é utilizada como uma das formas para articular tanto os tempos, como os espaços, com vistas a construir procedimentos didáticos e pedagógicos inovadores, que se articulem com as experiências de vida dos estudantes e os saberes técnicos-científicos (UFPA, 2015).

\section{PERCURSO METODOLÓGICO}

O trabalho tem como técnica para produção e análise de informações a pesquisa documental (GIL, 2017), com dados analisados numa perspectiva qualitativa e quantitativa (CASARIN; CASARIN, 2012). Os dados documentais iniciais foram obtidos a partir do Censo da Educação Básica de 2019 e do Censo da Educação Superior de 2018, onde mapeamos o percentual de professores que atuam na educação básica com a disciplina de Física no Estado do Pará, incluindo aqueles das escolas do meio rural, sem formação adequada, que nos permitiu conhecer ainda mais esse cenário. 
Além disso, analisamos o PPC do curso de Licenciatura em Educação do Campo (ênfase em Ciências da Natureza) ofertado pela UFPA no Campus de Altamira, que habilita os egressos para atuar nos anos finais do ensino fundamental com a disciplina de Ciências, e no ensino médio, com as disciplinas de Biologia, Física e Química (UFPA, 2015). Neste último caso, foi dado ênfase nas disciplinas do Núcleo Formação Específica, nas atividades curriculares de Física, que no caso do PPC analisado totalizam 4 (quatro) disciplinas, que denominamos por $\mathrm{AC} 1, \mathrm{AC} 2, \mathrm{AC} 3$ e $\mathrm{AC} 4$, sempre que a elas nos reportarmos. A opção por esses eixos justifica-se pelo fato de os mesmos concentrarem as disciplinas que possibilitam ao estudante do curso ter acesso aos conteúdos curriculares que também subsidiarão a sua prática quando o mesmo estiver imerso na atuação docente.

Foram analisadas as disciplinas que constituem o Núcleo Integrador, que inclui 8 (oito) Seminário Tempo Comunidade, 8 (oito) Seminário Tempo Universidade, 4 (quatro) Estágios Supervisionados e 1 TCC. Esse Núcleo subsidiará nossa análise para mapear possíveis aproximações dos conteúdos explorados na Formação Específica, com os modos de vida da comunidade, considerando que esse Núcleo se propõe a articular essa relação (UFPA, 2015).

\section{QUAL A FORMAÇÃO DO PROFESSOR QUE ATUA NA DISCIPLINA DE} FÍSICA NA EDUCAÇÃO BÁSICA?

A intenção desta seção é explanar sobre o perfil da formação do professor que atua com as disciplinas de Física na educação básica, mais precisamente no Ensino Médio nas escolas do campo. Inicialmente, cabe destacar que de acordo com os dados do Censo da Educação Superior, houve o aumento em 2018, como relação a 2017, de 8,9\% no número de ingressantes nos cursos de licenciatura. No entanto, mesmo com esse aumento no ingresso, o número de matrículas nesses cursos é de apenas 20,5\%, sendo inferior aos cursos de tecnólogos $(20,9 \%)$ e bacharelados (58\%) (BRASIL, 2019). Destarte não foi diferente nos cursos de Licenciatura em Física, onde o número de matrículas correspondia a apenas 1,8\% do total de cursos de licenciatura do país (BRASIL, 2019). Autores como Garcia e Higa (2012) expõem que um dos fatos para essa baixa procura decorre da desvalorização da profissão, materializada nos baixos salários e elevada carga de trabalho.

Aliado a esse baixo número de matrículas, tem-se outros dois fatores que influenciam no número de concluintes: a retenção e a evasão. No primeiro, 9,7\% dos 
alunos ficam retidos, ou seja, atrasam o seu percurso formativo e, no segundo, 71,8\% deles desistem do curso. Isso reflete no baixo número de professores que se formam em Física no país, fazendo com que a carência de profissionais formados na área, para atuar na educação básica, seja muito elevada (BRASIL, 2019; 2020a). Esse quantitativo de professores formados não dá conta de atender as demandas que emergem da educação básica, onde professores de diferentes formações e até mesmo sem formação atuam com a disciplina.

Esses dados são ratificados pelo Censo da Educação Básica de 2019, presentes no Gráfico 1 sobre a formação dos docentes da educação básica (BRASIL, 2020a). Por meio do gráfico, vemos que a adequação da formação docente (AFD) de Física (com licenciatura em Física ou complementação pedagógica ${ }^{5}$ em Física) que atua no ensino médio, por exemplo, corresponde a apenas 45,8\%. Há ainda o percentual 3,4\% dos que não possuem nem nível superior (BRASIL, 2020a; 2020c).

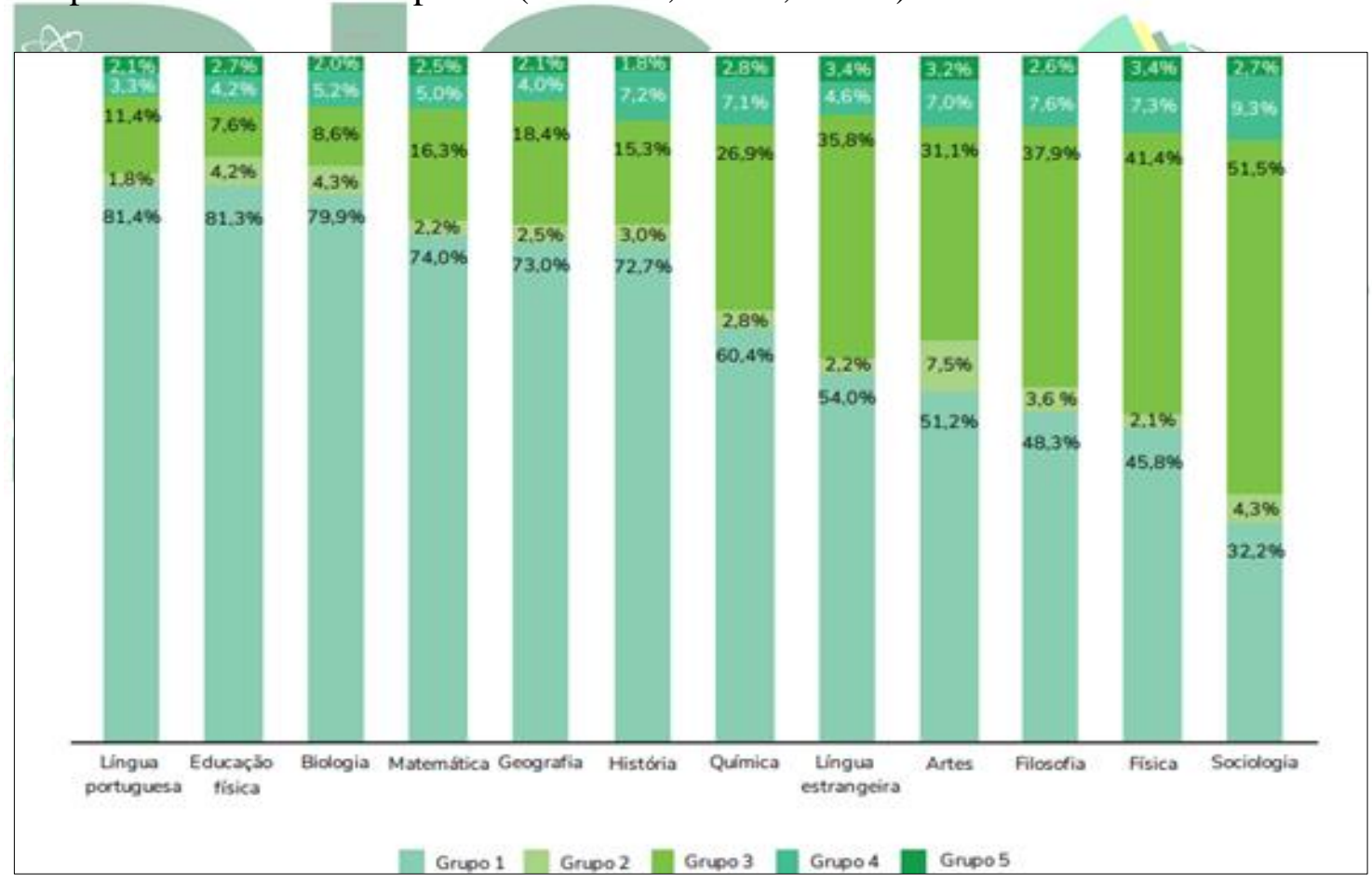

Gráfico 1 - Formação dos docentes na educação básica. Grupo 1: Licenciatura na mesma disciplina que leciona ou Bacharelado na mesma disciplina com curso de Complementação Pedagógica; Grupo 2: Bacharelado na disciplina correspondente, mas sem curso de Complementação Pedagógica; Grupo 3: Licenciatura em área diferente daquela que leciona ou bacharelado nas disciplinas da base curricular comum e curso de Complementação Pedagógica em área diferente daquela que atua; Grupo 4: Outra formação superior não considerada nas categorias anteriores; Grupo 5: Não possui curso superior. Fonte: Brasil (2020b).

\footnotetext{
${ }^{5}$ Resolução CNE/CP n ${ }^{\circ}$ 2, de $1^{\circ}$ de julho de 2015 (BRASIL, 2015).
} 
Quando nos reportamos aos indicadores da educação básica, observamos as discrepâncias apontadas de forma acentuada, como reflexos dessa não AFD. Isso faz com que sejam recorrentes os "improvisos" na escola básica, onde profissionais de diferentes formações, muitos deles sem licenciatura ou mesmo sem nível superior, atuam em disciplinas como Física, evidenciando a necessidade de se investir na formação de profissionais dessa área. Ao olharmos para os dados regionais, essa precariedade se acentua, principalmente aqueles referentes à atuação desses docentes nas escolas do campo, conforme observamos na Tabela 1.

Tabela 01: Adequação da Formação Docente (AFD) no Brasil, na Região Norte e no Pará

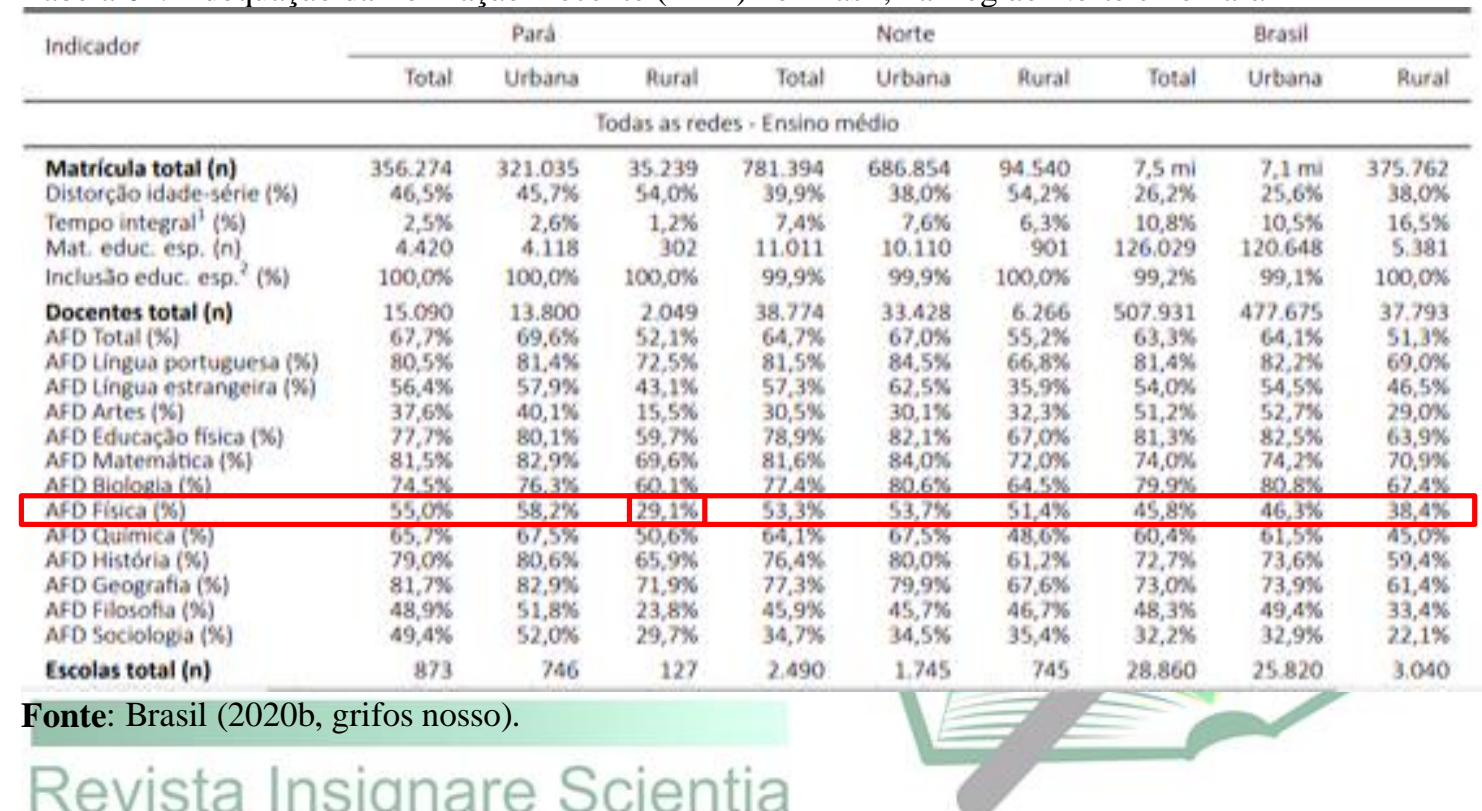

No estado do Pará temos 67,7\% de professores que tem AFD para atuar numa dada disciplina na educação básica. Em um estado com dimensões continentais, esse percentual chega próximo à metade, quando nos remetemos aos docentes que atuam nas escolas do campo, com 52,1\% sem formação na área que atua (BRASIL, 2020b). Por conseguinte, e de forma muito acentuada, essa discrepância é observada na disciplina de Física, onde existem apenas $55 \%$ de professores formados em Física e, nas escolas do campo, esses profissionais correspondem a apenas $29,1 \%$, estando apenas à frente da disciplina de Artes, que tem 15,5\% de AFD (BRASIL, 2020b). Os dados mostram ainda que isso não é uma realidade apenas do Pará, mas do próprio país, em que, no caso da Física, apenas $38,4 \%$ dos professores que atuam nas escolas do campo têm AFD.

Esses dados confrontam com aquilo que preconiza o Art. 62 da LDB, ao assegurar que a formação do docente que atua na educação básica deve ser em cursos de licenciatura (BRASIL, 1996) ou mediante cursos de Complementação Pedagógica (BRASIL, 2015), 
mostrando que a demanda por profissionais habilitados para atuar com a disciplina ainda é muito elevada. Nesse sentido, não raro encontramos professores formados em Matemática, ou em Biologia, bacharéis ou até mesmo sem formação em nível superior atuando em uma das disciplinas elementares da educação básica.

Moreira (2018, p. 73) reconhece essa lacuna e aponta a necessidade de expandir essas matrículas, bem como fazer mudanças tanto de currículo, quanto na prática docente, no interior dos cursos de licenciatura em Física. Não é nossa intenção apontar quais mudanças devem ser implementadas no interior deste curso, mas os dados indicam que esse cenário será mantido por muito mais tempo, o que continuará impactando de forma direta na educação básica, incluindo os povos do campo, que continuarão desassistidos de uma disciplina considerada fundamental para o desenvolvimento dos alunos. Dessa maneira, a licenciatura em Educação do Campo pode contribuir no acesso desses sujeitos aos conhecimentos mobilizados no interior dessa disciplina, que se relacionam aos fenômenos naturais, as transformações ocasionadas pelas práticas humanas e as tecnologias sociais relacionadas aos seus modos de vida.

\section{A FORMAÇÃO EM UM CURSO DE EDUCAÇÃO DO CAMPO PARA A DOCÊNCIA EM FÍSICA}

Os dados anteriores mostram que essa demanda de profissional habilitado para atuar com a disciplina de Física na educação básica tem reflexos mais acentuados nas escolas do campo. Nesse sentido, os cursos de licenciatura em Educação do Campo têm contribuído, mesmo que de forma inicial, para diminuir essa carência. No curso investigado, as primeiras duas turmas ofertadas concluíram no ano de 2018 (ano de seu reconhecimento com nota máxima pelo MEC), em 2019 foram mais duas turmas e em 2020 outras duas estão concluindo, com média de 27 alunos por turma.

No entanto, é preciso considerar alguns elementos importantes nesse processo, que foram instigados a partir de nossas experiências no interior do curso. Um deles diz respeito à carga horária do curso, equivalente a 3.300h, distribuída entre 4 (quatro) Núcleos ${ }^{6}$, a saber: 1) Formação Geral ${ }^{7}$, com 960h; 2) Formação Específica, com 1.200h;

\footnotetext{
${ }^{6}$ Os Núcleos congregam atividades curriculares, ao longo de 8 (oito) semestres letivos.

${ }^{7}$ Destina-se à “[...] formação geral em ciências da educação e em educação do campo, com subsídios para a formação intelectual, possibilitando reafirmação da identidade cultural dos sujeitos do campo articulando aspectos da docência, linguagens, memória e práticas educativas" (UFPA, 2015, p. 15)
} 
3) Integrador ${ }^{8}$, com 940h; e 4) Atividades Complementares, com 200h, pode ocasionar problemas na qualidade da formação docente. Como é possível observar o Núcleo de Formação Específica possui 1.200h, o equivalente à 36\% da carga horária do curso, sendo considerado o com maior percentual de todo o curso. No entanto, ele é subdividido em três habilitações que "credenciam" os egressos a atuarem nessas disciplinas escolares na educação básica: ciências (ensino fundamental), química, biologia e física (ensino médio). A carga horária dessas habilitações é apresentada no Quadro 01.

\begin{tabular}{|c|c|c|}
\hline Habilitação & Atividade Curricular & Carga Horária \\
\hline \multirow{7}{*}{ Biologia } & Biodiversidade & 60 \\
\hline & Biologia Básica & 60 \\
\hline & Ciclos Biológicos, Solo e Ambiente & 60 \\
\hline & Ciências do Ambiente & 60 \\
\hline & Fisiologia Humana e Doenças ligadas aos Sistemas & 60 \\
\hline & Genética e Ecologia Humana da Saúde e da Doença & 60 \\
\hline & Seres Vivos e o Ambiente & 60 \\
\hline 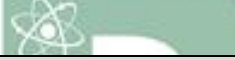 & Subtotal & $420 \mathrm{~h}$ \\
\hline \multirow{5}{*}{ Física } & AC1 - Física da Terra e do Universo & 60 \\
\hline & AC2 - Fundamentos da Física I & 60 \\
\hline & AC3 - Fundamentos da Física II & 60 \\
\hline & AC4 - Fundamentos da Física III & 60 \\
\hline & Subtotal & 240h \\
\hline V & Química Básica I & 60 \\
\hline \multirow{4}{*}{ Revímica } & Química do Solo e da Água & 60 \\
\hline & Química e Atmosfera & 60 \\
\hline & Química Orgânica éo Ser Húmano & 60 \\
\hline & Subtotal & $240 \mathrm{~h}$ \\
\hline & Total & $900^{9}$ \\
\hline
\end{tabular}

Fonte: Elaborado pelos autores, a partir dos dados de UFPA (2015)

Pelo quadro, vemos que há predominância de atividades curriculares para a habilitação em Biologia, com 7 atividades, totalizando 420h. Enquanto para a habilitação em Química e Física são 4 atividades, totalizando apenas 240h, cada uma. Há discrepância acentuada de carga horária entre as disciplinas das habilitações, mesmo

\footnotetext{
8 “visa à consolidação da formação numa abordagem multidisciplinar, mediante articulação das atividades curriculares Seminário de Tempo-Universidade/Tempo-Comunidade, Pesquisa e Prática Pedagógica, realizadas nos diferentes espaços formativos da Pedagogia da Alternância" (Idem)

${ }^{9}$ As disciplinas Educação em Ciências e Tecnologias (60h) e Etnociências (60h), Geometria Plana e o Espaço Agrário (60h) e Matemática para o Ensino de Ciências I e II (60h cada), transitam entre as três habilitações, dada a sua ementa, não se restringindo, portanto, a uma habilitação.
} 
considerando que conteúdos de ciências no ensino fundamental são os definidos como biologia.

Essa distorção de carga horária entre as habilitações que constituem o Núcleo, pode penalizar os objetivos do mesmo, que segundo o PPC:

Tem a finalidade de construir e desenvolver uma formação específica de qualidade, fundamentada em conhecimentos que articulem a relação teoria/prática a partir de componentes curriculares distribuídos em duas áreas epistemológicas (Linguagens e Códigos ou Ciências da Natureza), com o intuito de desenvolver habilidades e competências profissionais para o exercício docente em cada uma dessas áreas do conhecimento numa perspectiva multidisciplinar. (...) $\mathrm{Na}$ área de Ciências da Natureza estão os eixos dos fundamentos das ciências matemáticas, biológicas e físico-químicas (UFPA, 2015, p. 15).

Percebe-se que o objetivo do Núcleo é aprofundar conhecimentos inerentes à área de atuação do egresso, portanto espera-se que ao final do curso os alunos tenham uma sólida formação tanto na dimensão dos conteúdos específicos da ênfase quanto da dimensão didático-pedagógico, que poderia ser viabilizada por meio da ampliação da carga horária das mesmas, do planejamento integrado e por estratégias metodológicas interdisciplinares.

Além dessa baixa carga horária dedicada às disciplinas já ser um grande problema para a formação, pelo fluxograma do curso, as disciplinas específicas de Física, AC1 e AC2, são introduzidas a partir do $3^{\circ}$ semestre. Aos nos reportarmos às suas ementas percébemos que as mesmas seguem a lógica da física clássica, semelhante ao que se visualiza nos cursos de Física.

AC1- Movimento de uma dimensão, movimento em um plano, dinâmica da partícula, dinâmica da partícula II, trabalho e energia, conservação de energia, momento linear, colisão, cinemática da rotação, dinâmica. Transformação de energia mecânica em energia elétrica: implicações para a educação ambiental (UFPA, 2015, p. 38).

AC2 - Linguagem matemática da Física. Sistema de Unidade Internacional. A Física de Galileu: referenciais. Fundamentos da mecânica newtoniana. A Física de Einstein. Paradigmas da Física e suas relações com educação ambiental (UFPA, 2015, p. 38).

Nas mesmas ementas, buscamos possíveis desdobramentos da Física com outras áreas ou uma certa aplicação da mesma contextualizada com os modos de vida dos alunos, temos nas ementas uma relação com a educação ambiental em ambas. Esse fator é 
perceptível também quando olhamos para as ementas da AC3 e da AC4, ministradas no $4^{\circ}$ e $5^{\circ}$ Período do curso, respectivamente:

AC3 - Noções de eletricidade. Noções de eletromagnetismo. Tensão elétrica: a geração de energia e sua transmissão. Formas de transmissão e seus impactos na natureza: implicações para a educação ambiental (UFPA, 2015, p. 39).

AC4 - Teorias sobre a origem e evolução do universo. A energia e a constituição do universo. Recursos utilizados pelo homem para conhecer o universo. Estrutura do universo: galáxias, estrelas, planetas, satélites, cometas, etc. Leis do movimento: o equilíbrio dinâmico dos corpos celestes e considerações sobre energia. Propriedades físicas em escala cosmológica: distribuição espacial. O planeta Terra: origem e movimentos. Educação ambiental e sua relação com a localização do homem no universo (UFPA, 2015, p. 34).

A partir da abordagem feita dentro dos currículos apresentados, é bem possível que os alunos formados no interior desses cursos sigam a lógica apreendida no decorrer da formação: um levedo formalismo matemático, desconsiderando outras abordagens que podem ser feitas, inclusive de cunho pedagógico e até mesmo epistemológico, ou seja, o professor prima pela perspectiva da racionalidade técnica. Cabe, nesse caso, ao professor inserir elementos que sejam possíveis de dialogar com as demais disciplinas da área do conhecimento e com os saberes produzidos pelos sujeitos campesinos, a fim de trazer para o processo de formação desses alunos elementos dessa interação e inerentes aos seus modos de vida, ou que emergem desses contextos, como forma de potencializar a

\title{
formação. Insianare Scientia
}

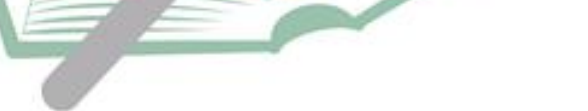

Como o curso se propõe a desenvolver a formação no âmbito da Pedagogia da Alternância, buscamos no Núcleo Integrador - que inclui os Tempos Comunidades (TC) ${ }^{10}$ além dos Estágios Supervisionados ${ }^{11}$-, se haveria entrecruzamento entre as atividades curriculares dos dois Núcleos, pois, de acordo com o PPC, esse Núcleo:

\begin{abstract}
visa à consolidação da formação numa abordagem multidisciplinar, mediante articulação das atividades curriculares Seminário de TempoUniversidade/Tempo-Comunidade, Pesquisa e Prática Pedagógica, realizadas nos diferentes espaços formativos da Pedagogia da Alternância. [...] permite o desenvolvimento transversal desses componentes curriculares tornando o fazer pedagógico mais qualitativo, dinâmico e transformador. Completa a carga horária deste Núcleo o Estágio Supervisionado, com 400 horas, executado como vivência e exercício profissional da docência [...], com orientação e
\end{abstract}

\footnotetext{
${ }^{10}$ São 8 Tempos Comunidades no curso, um a cada semestre letivo, com 30h cada um deles.

${ }^{11}$ No curso existem 4 Estágios Supervisionados com 100h cada um deles, que se subdividem em: 60h de formação/orientação no Tempo Universidade, $10 \mathrm{~h}$ de observação na escola/sala campo de estágio e $20 \mathrm{~h}$ de regência em sala de aula.
} 
acompanhamento de professores e articulado ao planejamento das instituições de ensino básico do campo.

Nota-se a partir desse Núcleo, que há intenção de compreender como se articulam os conteúdos da área específica com os saberes que emergem das experiências vividas pelos alunos nas suas comunidades de pertença nos diferentes espaços-tempos de aprendizagens preconizados pela Pedagogia da Alternância, que o curso desenvolve por meio dos TC's e TU's.

As atividades acadêmicas Seminário Tempo Comunidade I e II se propõem a fazer pesquisa-diagnóstico na comunidade de pertença do estudante e na escola dessa comunidade (UFPA, 2015). Nossa experiência na formação, permite dizer que esse diagnóstico tem buscado os aspectos históricos, sociais, econômicos, religiosos, as práticas agrícolas e os saberes tradicionais dessas comunidades, que subsidiarão o desenvolvimento dos TU seguintes.

No entanto, o TC III se destina à “Intervenção pedagógica em espaços escolares da comunidade: atuação do educador-pesquisador e observação das práticas socioeducativas nas escolas do campo" (UFPA, 2015, p. 65), onde os alunos desenvolvem pesquisas junto à gestão da escola, professores e alunos. Nesse TC busca-se conhecer se os conteúdos curriculares desenvolvidos nas aulas possuem relação com os modos de rida da comunidade onde a escola está inserida, bem como se o professor desenvolve metodologias específicas e diferenciadas, conforme preconiza a LDBEN e o Decreto $\mathrm{n}^{\circ}$ 7.252/2010, mas limita-se apenas aos anos finais do ensino fundamental, não sendo investigado as disciplinas da área de Ciências da Natureza no ensino médio.

Já no TC IV, os alunos devem restituir os dados obtidos no três TC anteriores, tanto para a comunidade escolar, quanto para a comunidade externa, incluindo a Secretaria Municipal de Educação do município desse aluno e o professor do curso que acompanha o desenvolvimento dessa atividade. Nesse momento de socialização, as pessoas que dela participam podem contribuir com a pesquisa apontando possíveis lacunas, ou com informações que não foram apontadas pelos alunos. É um momento muito rico, em que essas comunidades têm suas demandas expostas e conseguem diálogo, muitas delas pela primeira vez, com representantes da Secretaria de Educação.

Entretanto, nem sempre o professor das disciplinas específicas participa da orientação que dão os encaminhamentos aos alunos para o desenvolvimento dessas 
atividades ou não conseguem acompanhar a socialização desses levantamentos nos Seminários Tempo Universidade. Ou ainda, não conseguem acompanhar todos os alunos da ênfase nas suas comunidades de pertença, considerando o elevado número de comunidades a serem visitadas no decorrer do TC e, muitas delas, são de difícil acesso, além das limitações financeiras existentes no curso para que os professores se desloquem entre essas comunidades.

Logo, se a intenção desse diagnóstico é trazer para a formação as realidades e os saberes dessas comunidades, que poderiam ser explorados nas aulas de física, é preciso que as etapas que constituem essa alternância entre os tempos e espaços sejam construídas e executadas também pelos professores que atuam nos distintos Núcleos do curso, pois observamos, a partir das ementas dessas atividades, que não há menção sobre quais e como os conteúdos do Eixo Específico serão trabalhados visando essa articulação, ficando, nesse caso, a critério do professor que atua nessas disciplinas desse Núcleo fazer essa articulação.

Como já mencionado anteriormente, as disciplinas específicas de Física iniciam a partir do $3^{\circ}$ semestre do curso, se estendendo até o $6^{\circ}$. Portanto, ao desenvolverem os TC's iniciais e, considerando os apontamentos anteriores, não é possível afirmar que os alunos fazem abordagens dos conteúdos de Física quando estão imersos nas suas comunidades de pertença. Nesse caso, fica a critério do docente da disciplina, em conjunto com os alunos no decorrer dasua aula, fazerem o mapeamento das atividades desenvolvidas que podem mobilizar possíveis conteúdos curriculares que podem emergir dessas práticas e que poderiam ser explanados nos TC's seguintes.

Um dos momentos que isso ocorre é nas disciplinas de Estágios Supervisionados que iniciam no $5^{\circ}$ semestre do curso e ocorrem de forma concomitante aos demais TC's restantes; dois deles (os Estágios Supervisionados III e o IV) são destinados para o Ensino Médio, sem que seja mencionado na ementa em qual disciplina nesse nível o mesmo deve ocorrer. Pelas nossas vivências no interior do curso, temos optado por deliberar junto ao colegiado do curso, a partir do Núcleo Docente Estruturante (NDE), que um desses estágios sejam desenvolvidos na disciplina de Física. Nesse momento da formação, o desenvolvimento das atividades de orientação ocorre com a atuação de dois docentes, privilegiando um da formação específica e outro da formação didático-pedagógico. 
Além desses elementos do desenho curricular, a formação por área do conhecimento também nos coloca como desafio a abordagem por meio de metodologias que ultrapassem as barreiras disciplinares de conteúdos herméticos, não contextualizados, que não problematizam o próprio processo de construção do conhecimento e dos modelos científicos, e pouco reflexivos quanto às possibilidades de novos usos das tecnologias em favor da vida e do ambiente (MORIN, 2012). Nesse sentido, a formação por área do conhecimento deveria apresentar uma abordagem interdisciplinar e relacional dos aspectos sociais, físicos, químicos e biológicos, como por exemplo, os solos, a água, os ciclos biogeoquímicos, a saúde, a degradação ambiental e outros, que poderiam constituir temas geradores nessa dialética entre tempos-espaços da pedagogia da alternância.

No entanto, mesmo que o professor formador busque caminhos alternativos para adentrar numa outra perspectiva, esbarra no elemento tempo, pois como vimos, o tempo destinado para a formação nas disciplinas de Física não atende às necessidades de um público que teve pouco acesso à mesma no ensino médio. Nesse sentido, é imprescindível que, aliado à formação pedagógica, presente no curso, seja dada margem ampliada de carga horária para que se supere, efetivamente, o modelo de formação vigente, em que conteúdos relevantes na formação do futuro professor, que vai atuar com a disciplina escolar de Física, ocorra de forma plena, caso não, a formação adequada em todas as disciplinas da área do conhecimento acaba sendo penalizada. Além disso, é preciso considerar que dentro da Educação do Campo a perspectiva formativa não é pautada apenas na presença ou não de determinados conteúdos ou como ocorre a contextualização dos mesmos, mas dentro de um processo mais amplo, que envolve a formação de sujeitos com vistas a formação de um modelo de sociedade que respeite a diversidade, valorizando os saberes e os distintos modos de vida.

Cabe ressaltar que os egressos não têm garantia imediata de absorção pelas secretarias municipais ou estaduais de educação, pois os cursos que formam por área do conhecimento, como a Licenciatura em Educação do Campo, ainda encontram entraves para serem aceitos por tais secretarias, que ainda desenvolvem a seleção de forma disciplinar. Esse é uma outra luta que os movimentos, em conjunto com as instituições, vêm travando nos últimos anos.

\section{CONSIDERAÇÕES FINAIS}


Os cursos de Licenciatura em Educação do Campo no Brasil foram conquistas importantes para o Movimento da Educação do Campo, que conseguiu incluir no seio da universidade uma formação específica e diferenciada por meio da Pedagogia da Alternância. Essa conquista se amplia quando olhamos para os cursos que visam formar, por área de conhecimento, professores para atuar em disciplinas na educação básica que, historicamente, tem uma grande lacuna de profissionais habilitados, como é o caso de Física.

No entanto, ao visualizarmos no campo prático como essa formação vem ocorrendo, encontramos alguns entraves que contemplam de forma assertiva e plena a formação. Dentre eles temos a baixa carga horária destinada às atividades curriculares específicas, mais precisamente de Física, além dos conteúdos serem, predominantemente, da física clássica, agravado pela questão que os Tempos Comunidades destinados para essas abordagens não conseguem fazer a relação entre aquilo que foi produzido no Tempo Universidade. $\mathrm{O}$ aprofundamento dos conteúdos de Física é realizado quando os alunos estão imersos no Estágio Supervisionado, com o qual é destinado um deles para a disciplina de Física.

É necessário, portanto, fazer uma avaliação acerca desses entraves, buscando ampliar essa carga horária destinada às atividades curriculares de formação específica, como também rever a ementa dos conteúdos por elas abordados, assim como, refletir sobre a a abordagem interdisciplinar de determinados temas. Além disso, é necessário manter o processo permanente de avaliação do curso, envolvendo os docentes, discentes e os egressos, partindo das percepções que os mesmos têm acerca da forma como o curso vem sendo conduzido.

\section{REFERÊNCIAS}

ANDRADE, R. G. As dificuldades na aprendizagem de química no curso de educação do campo (ênfase em ciências da natureza), 2020. 35f. Trabalho de conclusão de Curso (Educação do Campo). Faculdade de Etnodiversidade, Universidade Federal do Pará, Altamira (PA), 10/07/2020.

ARROYO, M. G.. A Educação Básica e o Movimento Social do Campo. In: ARROYO, M. G.; CALDART, R. S.; MOLINA, M. C. (Orgs). Por uma Educação do Campo. Petrópolis, RJ: Vozes, 2009. 
BRASIL. Lei 9394/96 de 20 de dezembro de 1996. Institui as Diretrizes e Bases da Educação Nacional. Brasília, 1996. Disponível em:

http://www.planalto.gov.br/ccivil_03/leis/19394.htm. Acesso em 20 abril 2019

BRASIL. Ministério da Educação (MEC). Conselho Nacional de Educação (CNE). Câmara de Educação Básica (CEB). Resolução n. 1, de 03 de abril de 2002. Diretrizes Operacionais para Educação Básica nas Escolas do Campo. Brasília, 2002.

BRASIL. Decreto n. 7.352, de 04 de dezembro de 2010. Dispõe sobre a política de educação do campo e o Programa Nacional de Educação na Reforma Agrária - Pronera. Disponível em: http://www.planalto.gov.br/ccivil_03/_ato20072010/2010/decreto/d7352.htm. Acesso em: 22 jun. 2020.

BRASIL. Resolução CNE/CP n⿳ 2, de $1^{0}$ de julho de 2015 - Define as Diretrizes Curriculares Nacionais para a formação inicial em nível superior (cursos de licenciatura, cursos de formação pedagógica para graduados e cursos de segunda licenciatura) e para a formação continuada. Disponível em:

http://portal.mec.gov.br/index.php?option=com_docman\&task=doc_download\&gid=17 719\&Itemid=. Acesso em: 10 set. 2020.

BRASIL. Instituto Nacional de Estudos e Pesquisas Educacionais Anísio Teixeira (Inep). Censo da Educação Superior 2018: notas estatísticas. Brasília, 2019.

BRASIL. Instituto Nacional de Estudos e Pesquisas Educacionais Anísio Teixeira (Inep). Censo da Educação Básica 2019: notas estatísticas. Brasília, 2020a.

BRASIL. Instituto Nacional de Estudos e Pesquisas Educacionais Anísio Teixeira (Inep). Resumo Técnico: Censo da Educação Básica Estadual 2019 [recurso eletrônico]. Brasília, 2020b.

BRASIL. Instituto Nacional de Estudos e Pesquisas Educacionais Anísio Teixeira (Inep). Censo da Educação Básica 2019: Resumo Técnico. Brasília, 2020c.

BRASIL. Lei no 9.394, de 20 de dezembro de 1996. Estabelece as diretrizes e bases da educação nacional. Disponível em:

http://www.planalto.gov.br/ccivil_03/Leis/L9394.htm. Acesso em 22 jun. 2020.

BRICK, E. M. BORGES, M. G. A ideia de área de conhecimento: contribuições para pensar a peculiaridade da formação inicial nas licenciaturas em Educação do Campo no Brasil. In: XI ENCONTRO NACIONAL DE PESQUISA EM EDUCAÇÃO EM CIÊNCIAS - XI ENPEC, $n^{\circ}$ 11, 2017, Florianópolis (SC). Anais [...]. Florianópolis: UFSC, 03 a 06 jul. 2017. p. 1-10. Disponível em: http://www.abrapecnet.org.br/enpec/xi-enpec/anais/resumos/R1079-1.pdf. Acesso em: 03 set. 2020.

BRITTO, N. S. SILVA, T. G. R. Educação do Campo: formação em ciências da natureza e o estudo da realidade. Educ. Real. v. 40, n. 3, Porto Alegre, July-Set. 2015. Disponível em: https://doi.org/10.1590/2175-623645797. Acesso em: 03 set. 2020. 
BRITTO, N. S.. Educação do Campo, área Ciências da Natureza e Ensino de Biologia: questões, reflexões e ações para docência na Educação Superior e Básica. Revista de Ensino de Biologia da Associação Brasileira de Ensino de Biologia (SBEnBio), v. 8, p. 32-44, 2016.

CALDART, R. Licenciatura em Educação do Campo e projeto formativo: qual o lugar da docência por área? In: $5^{\circ}$ SEMINÁRIO NACIONAL DAS LICENCIATURAS EM EDUCAÇÃO DO CAMPO, nº 5, 2015, Laranjeiras do Sul (PR): UFFS, 08 a $11 \mathrm{dez}$. 2015. p. 1-10. Disponível em:

https://seminarionacionallecampo2015.files.wordpress.com/2015/09/licenciatura-emeducac3a7c3a3o-do-campo-e-projeto-formativo-qual-o-lugar-da-docc3aancia-porc3a1rea.pdf. Acesso em: 03 set. 2020.

CASARIN, H. C. S. CASARIN. S. J. Pesquisa científica: da teoria à prática. Curitiba; InterSaberes, 2012.

FREIRE, P. Pedagogia da autonomia: saberes necessários à prática educativa. São Paulo: Paz e Terra, 1996.

GARCIA, N. M. D; HIJA, I. Formação de professores de Física: problematizando ações governamentais. In: Educação: teoria e prática, Rio Claro (SP), 2012, v. 22, n. 40, p. 166-183. Disponível em:

https://biopibid.ccb.ufsc.br/files/2013/12/forma\%C3\%A7\%C3\%A3o-de-professores-defisica.pdf. Acesso em 03 set. 2020.

GIL, Antônio Carlos. Como elaborar projeto de pesquisa. 6. ed. São Paulo: Atlas, 2017.

HAGE, S. M.; SILVA, H. S. A.; BRITO, M. M. B. Educação superior do campo: desafios para a consolidação da licenciatura em educação do campo. In: Educ. rev. [online]. 2016, vol. 32, n. 4, p.147-174. https://doi.org/10.1590/0102-4698162036. Acesso em: 25 ago. 2020.

MEDEIROS, E. C. de, MORENO, G. de S., BATISTA, M. do S. X. Territorialização nacional da Educação do Campo: marcos históricos no Sudeste paraense. Educ. Pesqui., São Paulo, v. 46, e224676, 2020. Disponível em: https://doi.org/10.1590/s16784634202046224676. Acesso em: 18 out. 2020.

MOLINA, M. C.; HAGE, S. M. Política de formação de educadores do campo no contexto da expansão da educação superior. Revista Educação em Questão, v. 51, n. 37, p. 121-146, 15 abr. 2015. Disponível em: https://doi.org/10.21680/19811802.2015v51n37ID7174. Acesso em: 25 ago. 2020.

MOLINA, M. C; HAGE, S. M. Riscos e potencialidades na expansão dos cursos de licenciatura em Educação do Campo. RBPAE, v. 32, n. 3, set./dez. 2016, p. 805 - 828.

MOREIRA, M. A. Uma análise crítica do ensino de Física. In: Estudos Avançados, São Paulo (SP), v. 32, no 94, p. 73-80, 2018. Disponível em: http://dx.doi.org/10.1590/s0103-40142018.3294.0006. Acesso em: 04 set. 2020. 
MORIN, E. (org.). A religação dos saberes: o desafio do século XXI. 10 a ed. Rio de Janeiro: Bertrand do Brasil, 2012.

TENÓRIO, W.; FORMIGOSA, M.; ROCHA, C. G.; SANTANA, R. A formação e atuação docente na disciplina de ciências em escolas do campo na Amazônia Paraense. Revista Insignare Scientia - RIS, v. 2, n. 4, p. 158-179, 2019. Disponível em: https://doi.org/10.36661/2595-4520.2019v2i4.11021. Acesso em: 30 mai. 2020

UNIVERSIDADE FEDERAL DO PARÁ (UFPA). Faculdade de Etnodiversidade. Licenciatura em Educação do Campo. Projeto Pedagógico do Curso (PPC). Altamira (PA): UFPA, 2015.
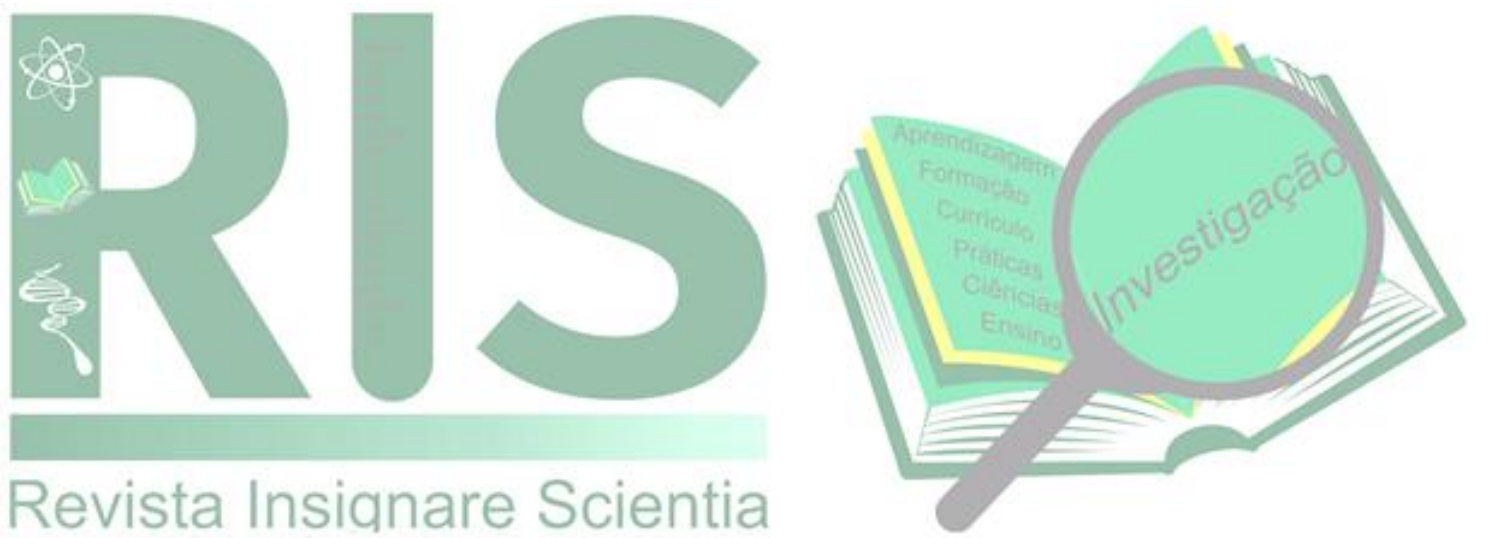